\title{
Binding of DNA origami to lipids: maximising yield and switching via strand-displacement
}

\author{
Authors: Es Darley $\ddagger^{1}$, Jasleen KD Singh $\ddagger^{2,3,4}$, Pietro Ridone ${ }^{1}$, Ali Abbas ${ }^{3,4}$, Shelley FJ Wickham ${ }^{* 2,4,5}$ and \\ Matthew AB Baker*1,6 \\ ‡equal contribution
}

1. School of Biotechnology and Biomolecular Sciences, University of New South Wales, Sydney, Australia.

2. The University of Sydney, School of Chemistry, Sydney, New South Wales, Australia.

3. The University of Sydney, School of Chemical and Biomolecular Engineering, Sydney, New South Wales, Australia.

4. The University of Sydney, The University of Sydney Nano Institute, Faculty of Science, Sydney, New South Wales, Australia

5. The University of Sydney, School of Physics, Sydney, New South Wales, Australia.

6. CSIRO Synthetic Biology Future Science Platform, Brisbane, Australia.

* To whom correspondence should be addressed: shelley.wickham@sydney.edu.au; matthew.baker@unsw.edu.au

\section{ABSTRACT}

Liposomes are widely used as synthetic analogues of cell membranes and for drug delivery. Lipid-binding DNA nanostructures can modify the shape, porosity and reactivity of liposomes, mediated by cholesterolmodifications. DNA nanostructures can also be designed to switch conformations by DNA strand displacement. However, the optimal conditions to facilitate stable, high-yield DNA-lipid binding while allowing controlled switching by strand-displacement are not known. Here we characterised the effect of cholesterol arrangement, DNA structure, buffer and lipid composition on DNA-lipid binding and strand displacement. We observed that binding was inhibited below pH 4, and above $200 \mathrm{mM} \mathrm{NaCl}$ or $40 \mathrm{mM} \mathrm{MgCl}$, was independent of lipid type (neutral/zwitterionic), and increased with membrane cholesterol content. For simple motifs, binding yield was slightly higher for double-stranded DNA than single-stranded. For larger DNA origami tiles, $4-8$ cholesterol modifications was optimal, while edge positions and longer spacers increased yield of lipidbinding. Strand displacement achieved controlled removal of DNA tiles from membranes, but was inhibited by overhang domains, which are used to prevent cholesterol aggregation. These findings provide design guidelines for integrating strand-displacement switching with lipid-binding DNA nanostructures. This paves the way for achieving dynamic control of membrane morphology, enabling broader applications in nanomedicine and biophysics. 


\section{INTRODUCTION}

DNA nanotechnology is an approach to designing and building nanostructures that self-assemble via DNA hybridisation (1). Since its development (2), a variety of two and three-dimensional DNA nanostructures have been created and described $(3,4)$ as well as environment-sensing mechanisms that allow DNA nanostructures to change state in response to external triggers (5). Alongside this, in the field of DNA computing, increasingly complex computational circuits have been realised with DNA molecules in solution, driven by the process of toe-hold mediated DNA strand displacement $(6,7)$.

Liposomes are aqueous vesicles bound by one or more bilayers of lipids. Due to their similarities to membrane bilayers in nature, liposomes have proven a powerful research tool for modelling cellular membranes in simplified synthetic systems. Liposomes can also be used to encapsulate therapeutic payloads for enhanced drug delivery (8). Various strategies for engineering liposomes for therapeutic applications have been developed in order to increase circulation time, allow targeted payload release or deliver a payload to a cell's cytosol $(9,10)$. For example, lipid nanoparticles are the delivery vehicle for the first two approved SARS-CoV2 vaccines, developed in record time in 2020, which deliver mRNA cargo (11).

Modification of DNA with hydrophobic chemical groups, such as cholesterol, has been used to enable lipid membrane binding (12). Such membrane-bound DNA nanostructures have been used to functionalise liposome surfaces (13), control the shape of liposomes by inducing membrane curvature and tubulation (14, $15)$ and form membrane-spanning nanopores that facilitate current flow $(16,17)$. DNA nanopores can have dimensions which exceed those of natural protein pores (18), and can incorporate mechanisms that regulate ion flow in response to external stimuli, termed gating $(19,20)$.

Despite the range of lipid-interacting DNA nanostructures that have been successfully realised to date, there are still a number of limitations (21). Cholesterol is widely used to mediate DNA-lipid interactions, but systematic experimental studies of the kinetics and energetics of how different cholesterol-modified DNA nanostructures insert into bilayers are lacking. Generally, large numbers of hydrophobic groups are thought to be necessary for spontaneous and stable membrane insertion to occur (Krishnan et al., 2016) and to overcome the substantial energy penalties associated with the insertion of membrane-spanning DNA nanopores (22). It has been observed that both the quantity and position of TEG-cholesterol anchors on DNA nanostructures can affect their affinity for lipid bilayers $(17,23)$. The yield of well-formed lipid-DNA structures is also generally low, which limits many potential applications (21). Monovalent and divalent cations are necessary buffer components for assembly and maintaining the stability of DNA duplexes and nanostructures $(24,25)$, yet are also known to affect the physical characteristics of membrane bilayers $(26,27)$ and may affect the binding activity of cholesterol-modified DNA. Finally, complex regulatory mechanisms that control 
membrane deformation with fast kinetics are found in many biological systems, such as synaptic fusion (28) and endocytosis (29), but are yet to developed in DNA-lipid systems.

Here we present a systematic optimisation of the number, position and geometry of cholesterol attachment sites on a DNA nanostructure, as well as buffer and lipid composition, to improve the efficiency of membrane binding and increase yield of well-formed structures. We have quantified the binding of cholesterol-modified DNA strands to synthetic liposomes using fluorescence microscopy, including the effects of $\mathrm{pH}$, ion concentration, membrane composition and cholesterol content. We investigated three types of DNA motif: a single-stranded DNA (ssDNA), double-stranded duplex (dsDNA), and a duplex with a short single-stranded DNA 'overhang' proximal to the cholesterol group, recently shown to reduce aggregation during nanostructure assembly (30). Next, we investigated the membrane binding efficiency of a cholesterol-modified DNA origami nanostructure using fluorescence microscopy and a high throughput gel-shift assay. The effect of cholesterol number, configuration and spacer distance between the DNA nanostructure and cholesterol, were tested. We then optimised strategies for achieving reversible membrane binding by controlled removal of membranebound DNA nanostructures using toehold-mediated strand displacement.

\section{MATERIALS AND METHODS}

\section{Preparation of Buffers and solutions}

Liposomes and DNA stocks were diluted in Liposome Buffer (210 mM D-Sorbitol [S1876, Sigma], 5 mM Tris$\mathrm{HCl}$ [T3253, Sigma], $\mathrm{pH} 7.5)$ containing $\mathrm{NaCl}$ [AJA465, Ajax-Finechem] (12.5 mM to $400 \mathrm{mM}$ ) and $\mathrm{MgCl}_{2}$ [AJA296, Ajax-Finechem] (0 mM to $80 \mathrm{mM}$ ) as required. For $\mathrm{pH}$-dependent experiments a modified Liposome Buffer (210 mM D-Sorbitol, $100 \mathrm{mM} \mathrm{NaCl}$ ) was used, with pH adjusted to 2, 4, 6, 7, 8 and 10 +/- 0.2 with 200 $\mathrm{mM} \mathrm{NaOH}$ or $\mathrm{HCl}$.

\section{Design and assembly of ssDNA and dsDNA}

DNA strands used for lipid-binding experiments were 23 nucleotides (nt) in length, and used as ssDNA, dsDNA, or dsDNA with a 5' 6-nt single stranded 'overhang' (dsDNA-6nt) (Supplementary Material). Synthetic DNA oligonucleotides (oligos) were purchased from IDT (Integrated DNA Technologies, Inc., USA). DNA sequences were designed using NUPACK design software (31) to prevent unwanted secondary structures. A previously published 6-nt overhang sequence was added to the $5^{\prime}$ end of oligos (30). Oligos were purchased modified at the $3^{\prime}$ end with a tetraethylene glycol cholesterol moiety (TEG-cholesterol), or 5' Alexa 647, Cy5 or Cy3 fluorophores.

DNA stocks $(100 \mu \mathrm{M}, 1000 \mathrm{x})$ were prepared using MilliQ water [Milli-Q, Millipore] and stored at $4^{\circ} \mathrm{C}$. DNA duplexes were annealed at $10 \mu \mathrm{M}$ final concentration in duplex buffer $(100 \mathrm{mM} \mathrm{NaCl}, 5 \mathrm{mM}$ Tris- $\mathrm{HCl}, \mathrm{pH}$ 7.5). 
Oligos were heated to $90^{\circ} \mathrm{C}$ for five minutes then cooled in a thermocycler at $5^{\circ} \mathrm{C} /$ minute for 15 minutes to $15^{\circ} \mathrm{C}$, and stored at $4^{\circ} \mathrm{C}$. For dsDNA assembly, unmodified complementary strands were added in a 3-fold excess to modified strands. DNA was diluted in extrusion buffer $(210 \mathrm{mM}$ sorbitol, $100 \mathrm{mM} \mathrm{NaCl}, 5 \mathrm{mM}$ Tris$\mathrm{HCl}, \mathrm{pH} 7.5$ ) to $100 \mathrm{nM}$ for lipid-binding experiments.

\section{Preparation of Liposomes}

Liposomes were produced with two lipid mixtures: (1) DOPE/DOPC liposomes [49.9\% 1-palmitoyl-2-oleoyl-snglycero-3-phosphoethanolamine (DOPE 18:1, 850725 P, Avanti), 49.9\% 1-palmitoyl-2-oleoyl-glycero-3phosphocholine (DOPC 18:1, 850375 P, Avanti)], (2) DPhPC liposomes [99.8\% 1,2-diphytanoyl-sn-glycero-3phosphocholine (DPhPC 850356P Avanti Polar Lipids)] (Supplementary Table 1). Both lipid mixtures were doped with $0.1 \%$ PE-rhodamine [1,2-dioleoyl-sn-glycero-3-phosphoethanolamine- $\mathrm{N}$-lissamine rhodamine $\mathrm{B}$ sulfonyl, 810150P Avanti Polar Lipids] for fluorescence imaging and 0.1\% PE-biotin [1,2-dioleoyl-sn-glycero-3phosphoethanolamine-N-biotinyl, 870282P Avanti Polar Lipids] for surface tethering. All percentages indicate weight to weight ratios. Liposomes with cholesterol were prepared by replacing either DPhPC (lipid type 2, above) or equal parts of DOPE and DOPC (lipid type 1, above) with cholesterol [700000P Avanti Polar Lipids]. All lipids stocks were dissolved in chloroform at $10 \mathrm{mg} / \mathrm{mL}$ and stored at $-20^{\circ} \mathrm{C}$.

Extruded liposomes (termed SUVs) were produced using a Mini-Extruder kit using $100 \mathrm{~nm}$ membrane pore size (Avanti Polar Lipids Inc., USA) according to the manufacturer's protocol (Supplementary Methods). Liposomes were then diluted 100 -fold to $0.1 \mathrm{mg} / \mathrm{ml}$ final lipid concentration in extrusion buffer (210 mM sorbitol, $100 \mathrm{mM} \mathrm{NaCl}, 5 \mathrm{mM}$ Tris-HCl, pH 7.5) prior to experiments.

Giant unilamellar liposomes (GUVs) were prepared by electroformation using the Vesicle Prep Pro machine (Nanion Technologies GmbH, Germany) using the default protocol as described previously (32) (Supplementary Methods). GUVs in electroformation solution were diluted 1:1 in buffer of $210 \mathrm{mM}$ sorbitol, $80 \mathrm{mM} \mathrm{NaCl}, 10 \mathrm{mM}$ Tris- $\mathrm{HCl}$, giving a final external solution of $210 \mathrm{mM}$ sorbitol, $40 \mathrm{mM} \mathrm{NaCl}, 5 \mathrm{mM} \mathrm{Tris}-\mathrm{HCl}$. Liposome dissolution was tested by titration of increasing concentration of the detergent Polysorbate-20 (Supplementary Figure 1).

\section{TIRF Fluorescence microscopy of extruded SUVs}

Surfaces for imaging were prepared using tunnel slides and BSA-biotin/avidin conjugation chemistry as described previously $(33,34)$. Surface-tethered SUVs were imaged using on a Zeiss Elyra PALM/SIM Microscope in Total Internal Reflection Fluorescence (TIRF) mode with a 63x/1.4 Oil Iris M27 oil immersion objective (Carl Zeiss AG, Germany) and Andor iXon 897 EMCCD camera (Oxford Instruments, United Kingdom). Two-channel fluorescence images were collected for rhodamine-liposomes (Ex/Em filters 561/570-650 plus 
$750 \mathrm{~nm}$ longpass) and fluorophore-tagged DNA (Ex/Em filters 642/655 nm long pass). Exposure times were $100 \mathrm{~ms}$ (lipid) and 33ms (DNA).

\section{Confocal fluorescence microscopy of electroformed GUVs}

DNA binding on GUVs was imaged using a Leica TCS SP8 DLS confocal microscope with HC PL APO CS2 63 x oil immersion objective lens, Acousto-Optical Beam Splitter, and programmable crystal-based beam splitter (Leica Microsystems GmbH, Germany). Two-channel images with rhodamine-liposomes (Ex/Em 561/569-611 nm), and Alexa647- DNA (Ex/Em 640/690-734 nm).

\section{Quantification of DNA-liposome binding from microscope images}

A custom macro script was developed using FIJI in ImageJ (35) to quantify the colocalisation of DNA and liposomes, based on the Manders Overlap Coefficient (36). An intensity threshold was chosen as 2 standard deviations above the mean pixel intensity in the liposome channel over all images from a single experimental condition. This threshold was then used to create a binary mask for assigning pixels as either liposome or nonliposome, and thus identify liposomes from the background (Supplementary Methods, Supplementary Figure $2 / 3$ ). This method was found to show no bias or correlation with liposome area (percentage coverage), in comparison with Pearson's correlation, which did show such bias (Supplementary Figure 4/5).

The mean pixel intensities of the DNA channel for the liposome and background areas were then compared, and used to calculate a colocalisation ratio, $C_{R}$, via:

$$
C_{R}=F_{D N A, \text { Lipid }} / F_{D N A, \text { Background }}
$$

Where $C_{R}$ is the reported colocalisation ratio, $F_{D N A, L i p i d}$ is the mean pixel intensity of the fluorescent DNA in the

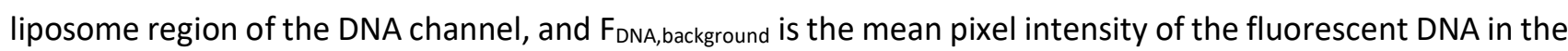
background region of the DNA channel (Supplementary Figure 3).

\section{Assembly of DNA origami nanostructures}

DNA sequences for DNA origami tile structure (37) were obtained using the Picasso software (Schnitzbauer et. al. 2017). The tile was folded using $10 \mathrm{nM}$ of scaffold (M13mp18 ssDNA, Bayou Biolabs) and 10x excess (100 $\mathrm{nM}$ ) of DNA staple strands (IDT) in folding buffer (5 mM Tris, $1 \mathrm{mM} \mathrm{EDTA}, 12 \mathrm{mM} \mathrm{MgCl}$, pH 8.0) and annealed over 3 hours $\left(80^{\circ} \mathrm{C}\right.$ for $15 \mathrm{~min}$, then $60-4^{\circ} \mathrm{C}$ in 56 steps at $\left.3 \mathrm{~min} 12 \mathrm{sec} / \mathrm{step}\right)$. Cy5 labelled DNA strands (IDT) and cholesterol-TEG modified DNA strands (IDT) were added to staple pools prior to annealing at $200 \mathrm{nM} \mathrm{(2x}$ excess relative to staple concentration). For fluorophore attachment to cholesterol staples, $400 \mathrm{nM}$ of fluorophore DNA was used ( $2 x$ excess to cholesterol DNA). All staples, plain and modified, were annealed in one-pot. All sequences used are supplied in the Supplementary Data. 
To decorate the DNA tile with cholesterols, 21-nt ssDNA handles (H1) were designed for hybridization with complementary cholesterol-TEG modified DNA strands (C1 or C2). To quantify binding of cholesterol-DNA to the tile, strand C1 was designed with a second binding domain for hybridisation of Cy5 fluorophore labelled DNA (F1) (Figure 1B-iii). For membrane binding experiments, strand C2, without the second domain, was used (Figure 1B-i). To label the tile with fluorophores for microscopy, separate 21-nt ssDNA handles, H2 were extended from the surface of the tile for hybridisation with Cy5 labelled ssDNA F2 (Figure 1B-ii). In this design for microscopy, the number of fluorophores on the tile is independent of the number of cholesterols. The positions of $\mathrm{H} 1$ on the tile are given in Figure $4 \mathrm{~A}$ and Supplementary Figure 9, and the positions of $\mathrm{H} 2$ are given in Supplementary Figure 8.

\section{Purification of DNA origami by agarose gel electrophoresis}

For analysis of membrane binding by gel, DNA origami tiles were purified by agarose gel electrophoresis (Bellot et. al 2011). Samples were loaded on $2 \%$ agarose gels and run for 2.5 hours at $60 \mathrm{~V}$ at $20^{\circ} \mathrm{C}$. Gel and running buffer used was $0.5 \times$ TBE buffer ( $45 \mathrm{mM}$ Tris boric acid, $45 \mathrm{mM}$ Tris base, $1 \mathrm{mM}$ EDTA, pH8) with $11 \mathrm{mM} \mathrm{MgCl}$, gels were pre-stained with SyBrSafe stain (Thermo Fisher Scientific). Gels were viewed under an LED Blue Light Transilluminator (Fisher Biotec) and the bands corresponding to the DNA origami tile were cut. The cut bands were transferred into Freeze 'N Squeeze DNA Gel Extraction spin columns (Bio-Rad), crushed and extracted by centrifugation at $18,000 \mathrm{~g}$ and $4^{\circ} \mathrm{C}$ for 10 minutes. The concentration of the recovered solution was determined using a Nanodrop (Thermo Fisher Scientific) to measure absorption at $260 \mathrm{~nm}$. DNA origami were stored at $4^{\circ} \mathrm{C}$.

\section{Purification of DNA origami by PEG precipitation}

DNA origami tiles were purified by PEG precipitation (Stahl et. al. 2014) for all microscopy experiments. The folded DNA origami tile sample was mixed at 1:1 ratio with PEG buffer (15\% PEG 8000 (w/v), 5 mM Tris, 1 mm EDTA, and $505 \mathrm{mM} \mathrm{NaCl}$ ) and incubated at $4^{\circ} \mathrm{C}$ for 30 minutes. The solution was centrifuged at $15,000 \mathrm{~g}$ at $4^{\circ} \mathrm{C}$ for 30 minutes. The supernatant was removed using a pipette, air dried and then dissolved in the buffer ( 5 mM Tris- $\mathrm{HCl}, 40 \mathrm{mM} \mathrm{NaCl}, 10 \mathrm{mM} \mathrm{MgCl} 2$ ).

\section{Gel-shift assay to quantify membrane binding of DNA origami}

Agarose gel shift assays were conducted to determine the extent of membrane binding of DNA origami nanostructures $(38,39) .10 \mu \mathrm{L}$ of $2.5 \mathrm{nM}$ gel purified DNA origami tile was incubated with $5 \mu \mathrm{L}$ of extruded SUVs (diluted 20x in $5 \mathrm{mM}$ Tris $-\mathrm{HCl}, 40 \mathrm{mM} \mathrm{NaCl}, 10 \mathrm{mM} \mathrm{MgCl}$ upon extrusion) for 30 minutes at room temperature. $10 \mu \mathrm{L}$ of sample was loaded onto a $2 \%$ agarose gel prepared in $0.5 \times$ TBE buffer ( $45 \mathrm{mM}$ Tris boric acid, $45 \mathrm{mM}$ Tris base, $1 \mathrm{mM}$ EDTA, pH 8.0) supplemented with $11 \mathrm{mM} \mathrm{MgCl}$. The gel was run at $60 \mathrm{~V}$ for 2.5 
hours at $20^{\circ} \mathrm{C}$, and imaged using Chemidoc MP Imager (Bio-rad). Images were obtained in the Cy5 channel and analysed using the Bio-Rad Image Lab software.

This assay allowed for the separation of unbound tiles from membrane bound tiles (Figure 4C). For each tile design, 2 gel lanes were run: (1) tiles incubated with liposomes (sample lane), (2) tiles only, no liposomes (control lane). The intensity of the tile band was compared between the sample and control lanes to quantify the extent of membrane binding. The ratio of the intensity of the tile band in the sample lane (+ liposomes, red box in Figure 4C.i.) to the intensity of the tile band in the control lane (- liposomes, black box in Figure 4C.i) was determined to calculate the percentage of bound tiles:

$$
T=\left(1-\frac{U}{B}\right) \times 100 \%
$$

where $T$ is the estimated percentage of tiles that are bound to the membrane, $U$ is the intensity of the tile band in the lane without liposomes, and B is the intensity of the tile band in the lane with liposomes. To account for experimental variation in loading of DNA into the gel, at least two repeats of each gel were conducted.

\section{Transmission electron microscopy of DNA origami}

$15 \mu \mathrm{L}$ of of $1 \mathrm{nM}$ (in $5 \mathrm{mM}$ Tris, $1 \mathrm{mM}$ EDTA, $12 \mathrm{mM} \mathrm{MgCl}$, $\mathrm{pH}$ 8.0) purified DNA origami tile sample was placed onto parafilm, a plasma treated carbon-coated TEM grid (Ted Pella EM grids from ProScitech) was placed onto the sample and left for $1 \mathrm{~min}$ for the sample to adsorb onto the grid. A $2 \mu \mathrm{L}$ droplet of $2 \%$ uranyl acetate solution was placed onto fresh parafilm and the grid was then quickly tapped onto the droplet and immediately tapped onto a filter paper to remove excess stain. This staining protocol was repeated three times. TEM imaging was performed using the JEOL JEM-1400 microscope, $120 \mathrm{kV}$. TEM micrographs of the DNA tiles were averaged using RELION (Scheres, 2012) (Supplementary Fig. 7).

\section{RESULTS}

\section{DNA origami nanostructure design and assembly}

The 2D rectangle DNA origami tile (Fig. $1 \mathrm{Ai}$ ) was chosen due to its ease of assembly and wide use in the field of DNA nanotechnology (Schnitzbauer et. al. 2017, Johnson-Buck et. al. 2014, List et. al. 2014). The tile consists of 24 parallel DNA helices folded using the M-13 scaffold and has dimensions of $60 \mathrm{~nm} \times 90 \mathrm{~nm} \times 2 \mathrm{~nm}$. Successful assembly of the tile and incorporation of fluorophore-modified staple strands was verified using agarose gel electrophoresis (Supplementary Figure 6) and transmission electron microscopy (TEM) (Fig. 1Aii and Supplementary Figure 7).

Imaging of DNA-liposome binding 
In TIRF microscopy of SUVs, fluorescent DNA was observed to colocalise with fluorescent liposomes only when modified with cholesterol (Fig. 2C). DNA without cholesterol was distributed evenly throughout the image independently of the position of liposomes (Fig 2A). Similarly, in confocal images of GUVs, cholesterolmodified DNA colocalised with GUVs (Fig. 2D) and plain DNA did not (Fig. 2B).

\section{Effect of buffer and lipid composition on DNA-liposome binding}

The effect of DNA origami buffer components on the binding of cholesterol-DNA to SUVs was quantified. The colocalisation ratios $\left(C_{R}\right)$ of cholesterol-modified SsDNA, dsDNA and dsDNA-6 nt were measured for varying [NaCl], [MgCl2] and pH, for 1:1 DOPE/DOPC liposomes and DPhPC liposomes, and compared to plain DNA controls (Fig. 3).

DNA that was evenly distributed throughout a slide independently of liposome location would be expected to produce a $C_{R}$ value of 1.0. Membrane-bound DNA, on the other hand, would be expected to produce a $C_{R}$ of greater than 1.0, as the concentration of DNA on liposomes is expected to be higher than the concentration on the background. For DNA without cholesterol, the $\mathrm{C}_{\mathrm{R}}$ was measured as $1.01 \pm 0.03$ for all $\mathrm{NaCl}, \mathrm{pH}, \mathrm{MgCl}_{2}$ and lipid conditions tested, indicating low non-specific interaction between the unmodified DNA and liposomes. In comparison, the colocalisation ratio for various cholesterol-DNA configurations across all conditions was significantly higher $\left(C_{R}=1.70 \pm 0.36, p<0.05\right)$, confirming that specific binding of cholesterolDNA to liposomes was observed, and that non-specific binding of plain DNA to liposomes was negligible.

For all three configurations of cholesterol-DNA (ssDNA, dsDNA, dsNDA-6nt) on both DOPE/DOPC liposomes and DPhPC liposomes, a significant decrease was observed in $C_{R}$ between $12.5 \mathrm{mM}$ and $400 \mathrm{mM} \mathrm{NaCl}$ and between $0 \mathrm{mM}$ and $80 \mathrm{mM} \mathrm{MgCl}_{2}$. Linear regression analysis for all three configurations on both liposome compositions showed a trend of decreasing colocalisation scores with increasing concentrations of $\mathrm{NaCl}$ and $\mathrm{MgCl}_{2}(95 \% \mathrm{Cl}$ of gradient $<0)$.

DNA-liposome binding was tested for $\mathrm{pH}$ values between 2 and 10 and the $\mathrm{C}_{R}$ of cholesterol-DNA was observed to decrease in highly acidic conditions. At $\mathrm{pH} 2$, the $\mathrm{C}_{\mathrm{R}}$ of all three configurations of cholesterol-DNA with both DOPE/DOPC liposomes (Fig. 3E) and DPhPC liposomes (Fig. 3F) decreased to a level similar to the noncholesterol control strands, and was significantly less than at all other $\mathrm{pH}$ values $(p<0.05)$. This indicates that solutions of $\mathrm{pH} 2$ inhibit membrane binding.

\section{Effect of DNA configuration on lipid binding}

Three configurations of cholesterol-DNA (ssDNA, dsDNA and dsDNA- $6 \mathrm{nt}$ ) were compared for binding to SUVs (Figure 3). The difference in mean colocalisation ratios for each of the three cholesterol-DNA configurations under all 44 conditions (Fig. 3A-I) was calculated (Fig. 3JK). Significant differences were observed in mean $C_{R}$ for the different DNA configurations. In both DOPE/DOPC liposomes and DPhPC liposomes, we found DNA to 
colocalise more for dsDNA than ssDNA, in the order $C_{R(d s D N A)} \approx C_{R(d s D N A-6 n t)}>C_{R(s s D N A)}$. When compared to dsDNA, the addition of the six nucleotide overhang in dsDNA-6 nt was observed to cause a modest but significant decrease in binding to DPhPC liposomes, but no significant decrease in binding to DOPE/DOPC liposomes (Fig. 3IJ).

\section{Effect of membrane cholesterol content on DNA-lipid binding}

Cholesterol content was increased between $0 \%$ and $40 \%$ by mass for both lipid compositions. For DOPE/DOPC liposomes, $C_{R}$ of all three configurations of cholesterol-DNA showed a significant increase between $0 \%$ and $40 \%$ cholesterol $(p<0.05)$. Linear regression analysis showed a trend of increasing $C_{R}$ across the observed range of membrane cholesterol content (gradient $95 \% \mathrm{Cl}>0$ ) (Fig. 3G).

For DPhPC liposomes, $C_{R}$ of cholesterol-tagged DNA increased to a maximum at $10 \%-20 \%$ membrane cholesterol, then decreased with further increasing cholesterol. All three configurations of cholesterol-DNA showed both a significant increase in $C_{R}$ between $0 \%$ and $20 \%(p<0.05)$ and a significant decrease in $C_{R}$ between $20 \%$ and $40 \%(p<0.05)$ (Fig. 3H).

\section{Effect of number of cholesterols on membrane binding}

First, the correct assembly of cholesterol-DNA (C1) to the DNA tile was verified using agarose gel analysis (AGE)(Fig. 4B). The tile was folded with either $0,1,2$, 4, 8 or 16 cholesterols (OC, 1C, 4C-LS, 8C, 16C) moieties (Fig 4A and Supplementary Figure 9). Cy5 fluorophore-labelled strand F1 is designed to hybridise to the tile only in the presence of cholesterol-DNA C1. A comparison was made of Cy5 intensity of the DNA tile band (normalised to SyBr safe stained DNA channel) for samples with different numbers of cholesterol-DNA sites. The normalised Cy5 intensity was found to increase with increasing cholesterol number (Fig. 4Bii). This successfully confirmed that more cholesterol-DNA strands attached to the tile as the number of handles $(\mathrm{H} 1)$ increased from 0 to 16 .

The effect of cholesterol number on membrane binding was then observed by AGE and fluorescence microscopy (TIRF). In AGE, the DNA tiles were observed to migrate through the gel matrix, while the liposomes remained in the wells (Supplementary Figure 10), in agreement with literature results using this technique (30). The percentage of tiles bound to the membrane was $52 \pm 5 \%$ for tile-0C, indicating there is some nonspecific membrane binding even in the absence of cholesterols (Figure 4C.ii and Supplementary Figure 11). A significant increase in percentage of tiles bound was observed from tile- $0 \mathrm{C}$ to tile- $8 \mathrm{C}(\mathrm{p}<0.01)$. Maximum binding of tiles to liposomes was observed for tile- $8 \mathrm{C}$ at $81 \pm 5 \%$.

For microscopy experiments, the maximum colocalisation of tile and liposomes was observed on tiles with four cholesterol groups ( $C_{R}=1.85 \pm 0.20$ ) (Fig. 4C.iii). A significant increase in $C_{R}$ was observed between $n=0$ 
and $n=4$ cholesterol groups $(p<0.05)$, with a trend of increasing colocalisation as the number of cholesterol groups was increased within this range (linear regression between $n=0$ and $n=4$ : gradient $95 \% \mathrm{Cl}>0$ ). For the control, with no cholesterol, $C_{R}=1$, indicating there is equal amount of DNA in the background and on the liposome. Linear regression analysis across $n=4, n=8$ and $n=16$ showed a decreasing trend as the number of cholesterol groups was increased (gradient $95 \% \mathrm{Cl}<0$ ), however there was no significant difference in the means from pairwise testing.

\section{Effect of cholesterol geometry on membrane binding}

We next investigated the effect of cholesterol-DNA geometry on membrane binding. Two different geometries were compared: Large Square (4C-LS) and Small Square (4C-SS), as shown in Fig. 4A.i. In the LS configuration, four cholesterol anchors were positioned along the edge of the tile. The separation between the handles in the $4 \mathrm{C}$-LS configuration is $80 \mathrm{~nm}$ along the long edge and $45 \mathrm{~nm}$ along the short edge of the tile. In the 4C-SS configuration, four cholesterols anchors were positioned at the centre of the tile, with a separation of $5 \mathrm{~nm}$ between the handles. The percentage of tiles bound to the membrane was $69 \pm 12 \%$ and $57 \pm 9 \%$ for 4 C-LS and $4 \mathrm{C}$-SS configurations, respectively, using the gel-shift assay (Fig. 4Di and Supplementary Figure 12). The percentage of tiles bound non-specifically in the no cholesterol sample was $53 \pm 8 \%$, similar to results discussed in the previous section. In this case, the differences in membrane binding between the no cholesterol control, the LS and the SS geometries were found not to be statistically significant.

For the microscopy assay, $C_{R}$ of $1.25 \pm 0.04$ and $1.15 \pm 0.03$ were obtained for the 4C-LS and 4C-SS configuration, respectively ( $t$-test $p<0.05$, Fig $4 \mathrm{Dii}$ ). The extent of cholesterol attachment for the $4 \mathrm{C}$ - $\mathrm{LS}$ and $4 \mathrm{C}$ SS geometries were measured by AGE (method as above, Supplementary Figure 13) to determine if the difference observed in membrane binding between these samples was due to different levels of cholesterol attachment to the tile. No differences in cholesterol attachment were observed for the two tile configurations, suggesting that the differences observed in lipid binding were due to the different geometrical arrangements of the cholesterols on the tile.

\section{Effect of spacer length between cholesterol and tile on membrane binding}

Next, the effect of the spacer length between the cholesterol and the tile on membrane binding was observed. Seven different spacer designs were tested: Dt1.4, Dt6.1, Dt8.1, Pt8.1, Pt8.5, Pt13.2, and Dt15.2, where the number in the design name gives the distance between the cholesterols and the tile, e.g. Dt15.2 represents an estimated spacing of $15.2 \mathrm{~nm}$. The initial ( $\mathrm{Dt}$ or Pt) refers to the positioning of the toehold relative to the cholesterol. The toehold was either positioned distal to the cholesterol (Dt) or proximal to the cholesterol (Pt).

Membrane binding experiments were performed using the gel shift assay (Figure 5B.i and Supplementary Figure 14). Of the seven designs tested, the lowest percentage of bound tiles was observed for Dt 1.4 at $48 \% \pm$ 
$27 \%$. The maximum percentage of bound tiles was observed for Dt15.2 at $89 \% \pm 9 \%$. Percentage of bound tiles for Dt6.1, Dt8.1, Pt8.1, Pt8.5, Pt13.2 was at $50 \pm 15 \%, 62 \pm 20 \%, 67 \pm 23 \%, 80 \pm 23 \%$ and $86 \pm 15 \%$, respectively. The control with no cholesterols had $40 \pm 22 \%$ tiles bound to the membrane in this experiment. For microscopy, only three designs were selected: Dt1.4, Pt8.5 and Dt15.2. $C_{R}$ of $1.07 \pm 0.05,1.15 \pm 0.04$ and $1.24 \pm 0.04$ were obtained for Dt1.4, Pt8.5 and Dt15.2, respectively (Fig. 5Bii).

\section{Effect of toehold position on strand displacement of cholesterol-DNA from DNA origami tiles}

The effect of toehold position on releasing DNA tile binding to SUVs by strand displacement was then investigated. A 10-nt toehold was used for strand displacement of the tile from SUVs, to facilitate displacement of the $\mathrm{C} 2$ cholesterol strand from the tile (Fig. 1C). The toehold was designed to be either proximal (Pt) or distal (Dt) to the cholesterol modification.

Strand displacement was validated by folding DNA tiles with cholesterols and fluorophore (Cy5) such that the fluorophore attachment was dependent on the cholesterol attachment, similar to earlier experiments used to confirm cholesterol attachment (Fig 1Biii, Fig. 4B). The strand arrangement for each of the different designs and their toehold positions is shown in Fig $6 \mathrm{Ai}$.

Toehold-mediated strand displacement of the cholesterol strand from the DNA tile was first validated without any binding to SUVs. When displacement strand D1 is added, it is expected to bind to the toehold on the handle $\mathrm{H} 1$ and initiate branch migration, displacing the C1-F1 complex. It was confirmed that strands C1-F1 were displaced from the tile on addition of D1, as indicated by decrease in Cy5 intensity of the DNA tile band in AGE (Figure 6A.iii, Supplementary Figure 15).

Displacement efficiency was compared at room temperature (RT) and $37^{\circ} \mathrm{C}$. The percentage of $\mathrm{Cy} 5$ on the tile was determined from the gel as shown in Fig. 6Aiii. The percentage of Cy5 on the tile for the no displacement control was taken as $100 \%$ and the percentages for the displacement samples were calculated relative to this. Greater displacement was observed for designs with the toehold distal to the cholesterol groups (Fig. 6Aiii and Supplementary Figure 15). Temperature had no effect on the displacement for the designs with distal toeholds, which were all highly efficient, decreasing from $100 \%$ to $<3 \%$ for all conditions tested. In contrast, displacement efficiency of designs with toehold proximal to the cholesterol groups showed temperature dependence. Only partial displacement was observed at room temperature (decrease from $100 \%$ to $34-39 \%$ ), with improved displacement at $37^{\circ} \mathrm{C}(100 \%$ to $0-9 \%)$.

\section{Effect of toehold position on strand displacement of DNA-tiles from liposomes}

Strand displacement of lipid-bound DNA tiles was then tested. For these experiments, cholesterols were attached to the tile (Figure 1Bi) independently of the fluorophores (Figure 1Bii). The effect of strand 
displacement of the cholesterol from the tile was compared before (pre-displaced) and after (displaced) incubation with liposomes.

A subset of designs previously tested for lipid binding (Figure 5B) and strand displacement in lipid-free conditions (Fig. 6Aiii) were selected, consisting of Designs Dt1.4, Dt 15.2 and Pt8.5. Dt1.4 had shown poor membrane binding but efficient strand displacement in lipid-free conditions. Dt15.2 had both high membrane binding and efficient strand displacement in lipid-free conditions. Pt8.5 had high membrane binding but inefficient strand displacement at room temperature in lipid-free conditions.

The percentage of lipid bound tiles for each design was determined by gel analysis for each experimental condition (Fig. 6B and Supplementary Figure 16). The results show Dt1.4 had poor initial membrane binding (32\%), which made it difficult to determine if there was a change in binding after strand displacement (38\%, displaced, 33\%, pre-displaced). Dt15.2 was observed to have both high initial membrane binding (86\%) and a decrease in binding on strand displacement indicating successful displacement (39\%, displaced, 36\%, predisplaced). Pt8.5 had moderate initial membrane binding (61\%) and successful strand displacement (18\%, displaced, 15\%, pre-displaced). Comparing pre-displaced and displaced values, for all samples no significant effect was observed on changing the order of lipid binding and displacement. Hypothesised interactions of Dt1.4, Dt15.2 and Pt8.5 for both the bound and unbound tiles are proposed in Supplementary Figure 18.

\section{DISCUSSION}

Our comparison of the lipid-binding yield of simple DNA motifs (ssDNA, dsDNA, dsDNA-6nt) and large DNA origami tiles (7249 bp) modified with cholesterol defines a range of experimental conditions for which yield is independent of external buffer and lipid composition. Conveniently, we found that within this range, conditions can be selected based on the requirements of the DNA nanostructures or other system components.

DNA origami buffers are broadly compatible with liposome binding. DNA origami nanostructures often require specific ionic buffer conditions. Divalent cations such as $\mathrm{Mg}^{2+}$ stabilise DNA duplexes during nanostructure folding (40) and increase stability by inhibiting the electrostatic repulsion between DNA strands $(24,41)$. Some DNA nanostructures are designed to change shape in response to changes in ion concentration and $\mathrm{pH}$, acting as sensors (5). While changes in external buffer can cause changes in liposome membrane density and diffusivity (26) (27), within the ranges tested here, addition of $\mathrm{Na}^{+}(0-200 \mathrm{mM})$ and $\mathrm{Mg}^{2+}(0-40 \mathrm{mM})$, resulted in only a small decrease in lipid-binding yield, and no increase in non-specific binding of unmodified DNA was observed for any ionic condition. 
Both DOPE/DOPC and DPhPC lipid mixtures were found to work well for DNA-lipid binding. DNA is highly negatively charged, while liposomes formed from DPhPC are neutral, and liposomes from DOPE/DOPC are zwitterionic, and expected to be positively charged below pH 3.5 and negatively charged above pH 8 (42). We observed no change in lipid-binding yield or non-specific binding across the range $\mathrm{pH} 4-10$ for both neutral or zwitterionic lipids, which suggests lipid ionisation does not play a significant role in these conditions. However, we found that cholesterol-mediated DNA-lipid binding was completely inhibited in acidic conditions (< pH 4). Hydronium ions $\left(\mathrm{H}_{3} \mathrm{O}^{+}\right)$are known to promote lipid-lipid binding interactions within a bilayer (26) and affect behaviour of water molecules at the membrane-water interface (27). This could potentially lead to the inhibited binding observed here in strongly acidic conditions (40).

Interestingly, we found that increasing the cholesterol content of lipid mixtures above $20 \%$ increased the binding of DNA to DOPE/DOPC liposomes but slightly decreased binding to DPhPC liposomes. Cholesterol induces dense packing of phospholipids, reducing liposome permeability and increasing stability (43). Cholesterol also stabilises the structure of some membrane proteins and promotes highly curved membrane intermediates during fusion (44). Branched chain lipids like DPhPC occupy a greater area per molecule within a bilayer compared to linear-chain lipids such as DOPE and DOPC (45), and DPhPC has a lower cholesterol saturation limit than DOPE (46). Thus, the increased DNA-lipid binding that we observed with increasing cholesterol on DOPE/DOPC liposomes could be due to increased stability of the DNA-conjugated cholesterol in the membrane. The lower cholesterol saturation limit of DPhPC could explain why no further increase in lipid-DNA binding was observed above $20 \%$ cholesterol on DPhPC liposomes.

For small DNA motifs, dsDNA bound more efficiently to liposomes than ssDNA, and the addition of a 6-nt ssDNA overhang had minimal effect. Membrane-bound ssDNA has been observed to lie close to the surface of lipid bilayer membranes in fluorescence studies (48), while dsDNA remains in a stable position protruding normal to the membrane surface (49). Thus, the orientation difference of dsDNA compared to ssDNA may result in improved binding. The addition of a $6 \mathrm{nt}$ overhang on cholesterol-tagged dsDNA strands has been proposed to assist during nanostructure assembly by inhibiting strand aggregation (30). Inclusion of a $6 \mathrm{nt}$ overhang next to the cholesterol group resulted in a minor, but significant decrease in binding only on DPhPC liposomes, and not for DOPE/DOPC. This suggests there would be no large penalty from routine incorporation of overhangs on membrane-targeting nanostructures, but possible effects arising from other lipid compositions may need to be considered.

We measured the number of cholesterols present on our DNA origami tile using fluorescence labelling and observed a non-linear increase in fluorescence as the number of cholesterols was increased. This non-linear increase in fluorescence could possibly be due to non-linear range of detection provided by the gel analysis (Schröder et al., 2008) or self-quenching of the Cy5 fluorophores in close proximity on the tile (Berlier et al., 
2003; Hahn et al., 2001), or from incomplete occupation of the $\mathrm{H} 1$ handles by cholesterol-strands (Strauss et al., 2018). Assuming incomplete occupation and linear fluorescence intensity per handle for low numbers $(n=$ $0-4)$, we are able to estimate a lower bound for the actual cholesterol number in the $n=16$ sample. Linear regression across 0 to 4 handles estimates that our occupancy is $69 \%$ (for 16 cholesterols, our occupancy was 11 cholesterols with $[7,21]$ at $95 \% \mathrm{Cl})$. This closely matches previous reports for mean staple occupancy of DNA origami tiles, which was measured as $72 \%$ for the same $10 x$ staple excess folding conditions (Strauss et al., 2018).

The number of cholesterol groups on a DNA origami tile had a large effect on binding yield. Adding a large number of hydrophobic groups has been shown to be necessary for overcoming the energy penalty associated with pore formation (17), and beneficial for maintaining stable insertion of a transmembrane nanopore (50). However, a large number of cholesterol groups may inhibit the membrane-binding function of cholesteroltagged DNA nanostructures by inducing aggregation (30) or structural deformities (51). We found in our AGE measurements that a global optimum for membrane binding occurred with there were $n=4$ cholesterols. However, this was dependent on which assay was used: an optimum number of cholesterols of 8 was observed with the gel-shift assay and an optimum number of 4 was observed with the microscopy.

We suggest that our observation of an optimal cholesterol number in these experiments is due to intra-tile and inter-tile transient binding of cholesterols. List and colleagues (51) showed that hydrophobic interactions between a large number of cholesterols (i.e. 35 cholesterols) on the DNA tile can result in the folding of the tile. Here we did not observe deformation or aggregation of the tile on folding with higher cholesterol numbers (Figure 1Ai, Figure 4Bi). However, it is possible that transient hydrophobic interactions occur between the cholesterol groups, which are not detected by gel or TEM. This would have the effect of decreasing the availability of cholesterols for binding to liposomes, and explain the decrease observed in membrane binding in the gel-shift assay and microscopy.

The difference in optimal cholesterol number obtained from the gel-shift assay and the microscopy is likely due to the different tile purification methods used. For the gel-shift assay, the tiles were gel purified. For microscopy, the tiles were purified by PEG precipitation to achieve higher concentrations of tile. PEG precipitation results in more aggregation compared to gel purification (Supplementary Figure 17). Higher aggregation results in more interaction between the tiles, and in turn, is expected to decrease membrane binding.

We found that positioning cholesterols along the edge of tile resulted in more binding compared to cholesterols positioned at the centre of the tile, consistent with a previous study (23). We also found that the membrane binding of tiles increases as the spacing between the cholesterols and the tile increases. These trends are likely due to greater accessibility of the cholesterols at larger distances from the tile, and located 
at the edges of the tiles. The tile is flexible (52) and can fold, and the centre of the tile is more likely to be hidden compared to the edges. This may limit the accessibility of the cholesterols positioned at the centre and result in decreased membrane binding.

For all the results above, some non-specific binding was observed with the control tile (no cholesterol) in the gel-shift assay. However, the amount of non-specific binding varied from gel to gel, and was found to vary between preparations of SUVs. Percentages of no-cholesterol tiles bound to the SUVs ranged from $15 \%$ to $60 \%$ across all the gels run in all different experiments. To control for this, our samples were always compared within gels, not between gels. Generally, microscopy experiments had smaller error ranges, while gel assays had larger errors but were higher throughput and useful for comparing large numbers of conditions.

We found that toehold-mediated strand displacement could be used to remove cholesterol modified strands from the DNA tile with high efficiency, but that displacement efficiency decreased if the cholesterol was positioned directly adjacent to the toehold. This is likely due to the interaction of the toehold with the cholesterol group when it is in proximity. Previous work by Ohmann and colleagues showed that an overhang placed next to a cholesterol can interact with it to reduce aggregation (30). An increase in temperature from room temperature to $37^{\circ} \mathrm{C}$ increased the displacement efficiency of these proximal designs, to a similar value as designs where the cholesterol was located distal to the toehold.

Toehold-mediated strand displacement was shown to remove DNA tiles from liposomes, by separating the tile from the cholesterol strand. In this case, the cholesterol-modified DNA strand is expected to remain docked to the liposome. For cholesterol displacement of tiles already bound to liposomes, displacement was efficient for cholesterols positioned both proximal and distal to the toehold. This is in contrast to strand displacement in the absence of liposomes, and where proximal toeholds had reduced efficiency. When the tile binds to the liposome, we expect the cholesterol to insert into the bilayer. This may result in less interaction between cholesterol and toehold, making a more accessible toehold, facilitating more efficient strand displacement (Supplementary Figure 18). We expected to see reduced displacement efficacy for designs with shorter linkers (eg. Dt1.4 compared to Dt15.2, Pt8.5), because tight binding of the tile to the liposome may sterically hinder strand displacement. However, results here were dominated by the strong effect of linker length on initial binding yield. The short linker design had very low initial yield, comparable to non-specific binding, and so it was not possible to detect if there was a decrease on strand displacement with the gel shift technique.

\section{CONCLUSION}

In this work, we have tested different lipid species and DNA configurations to screen for optimal conditions to promote DNA-lipid binding. Our results suggest that lipid type, $\mathrm{pH}$ and DNA configuration are the most important parameters to consider when optimising for the binding of DNA strands to liposomes, whereas mono- and divalent- salt concentration play a minor role. 
Our results have shown that the membrane binding of DNA nanostructures to liposomes can be optimised by changing the cholesterol number, cholesterol configuration and cholesterol distance from the DNA nanostructure. We found that the optimal number of cholesterols for membrane binding of a 2D DNA origami tile is between 4 and 8 , and that membrane binding is more favourable when cholesterol groups are placed at the edge of the tile compared to the centre of the tile. A larger linker length between the tiles and the cholesterol also results in greater membrane binding.

We demonstrated reversible membrane binding of the DNA nanostructures onto liposomes using toehold mediated strand displacement. The efficiency of strand displacement is reduced if the toehold is adjacent to the cholesterol in unbound DNA nanostructures, but not for lipid-bound DNA nanostructures.

Future work could extend the findings from this work to more complex 3-dimensional DNA nanostructures with greater functionality. Generally, there is a trade-off between increasing the lipid binding yield and decreasing aggregation. The flexibility of the $2 \mathrm{D}$ tile plays a role in aggregation, and so the greater rigidity of 3D DNA origami nanostructures may be an advantage. We anticipate our findings can provide guidelines for the design of more complex membrane binding DNA nanostructures with broader applications in nanomedicine, nanotechnology, and nucleic acid research. 
A $\mathrm{i}$

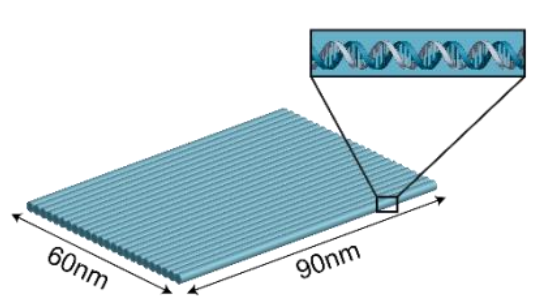

ii

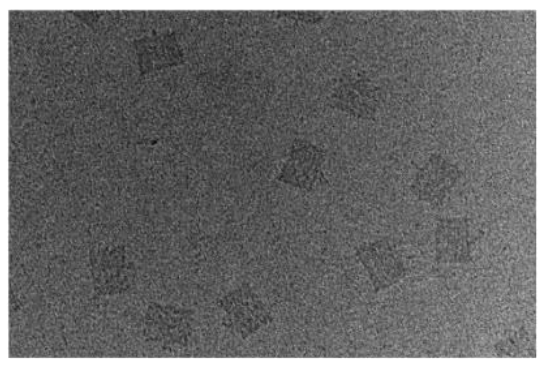

iii

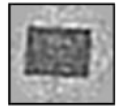

iv

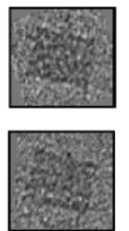

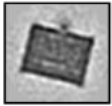

(3)

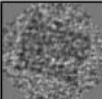

B
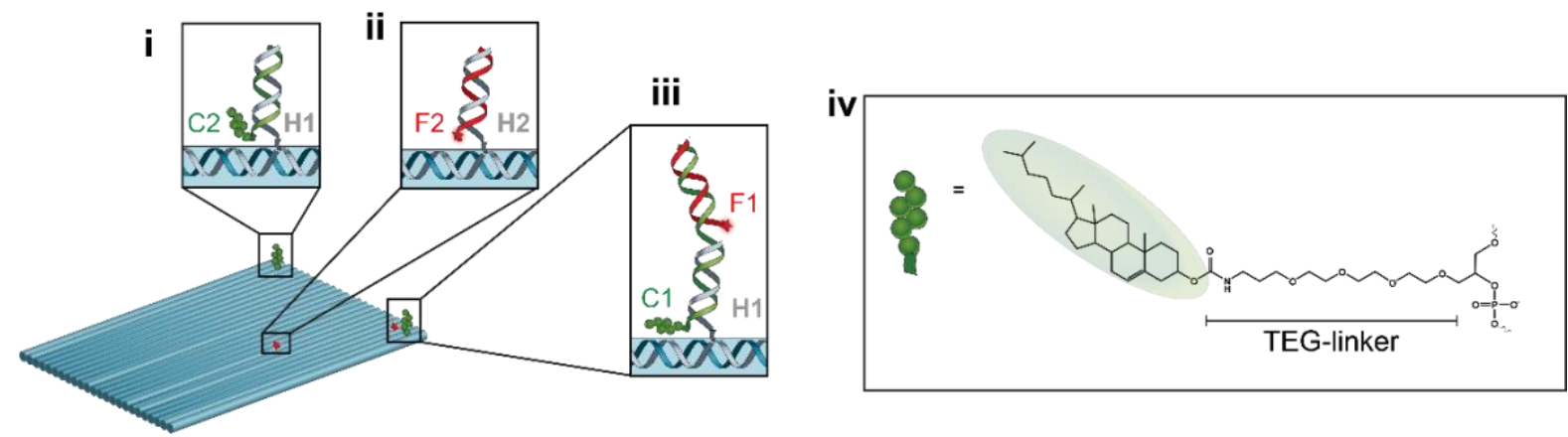

C i

ii

iii
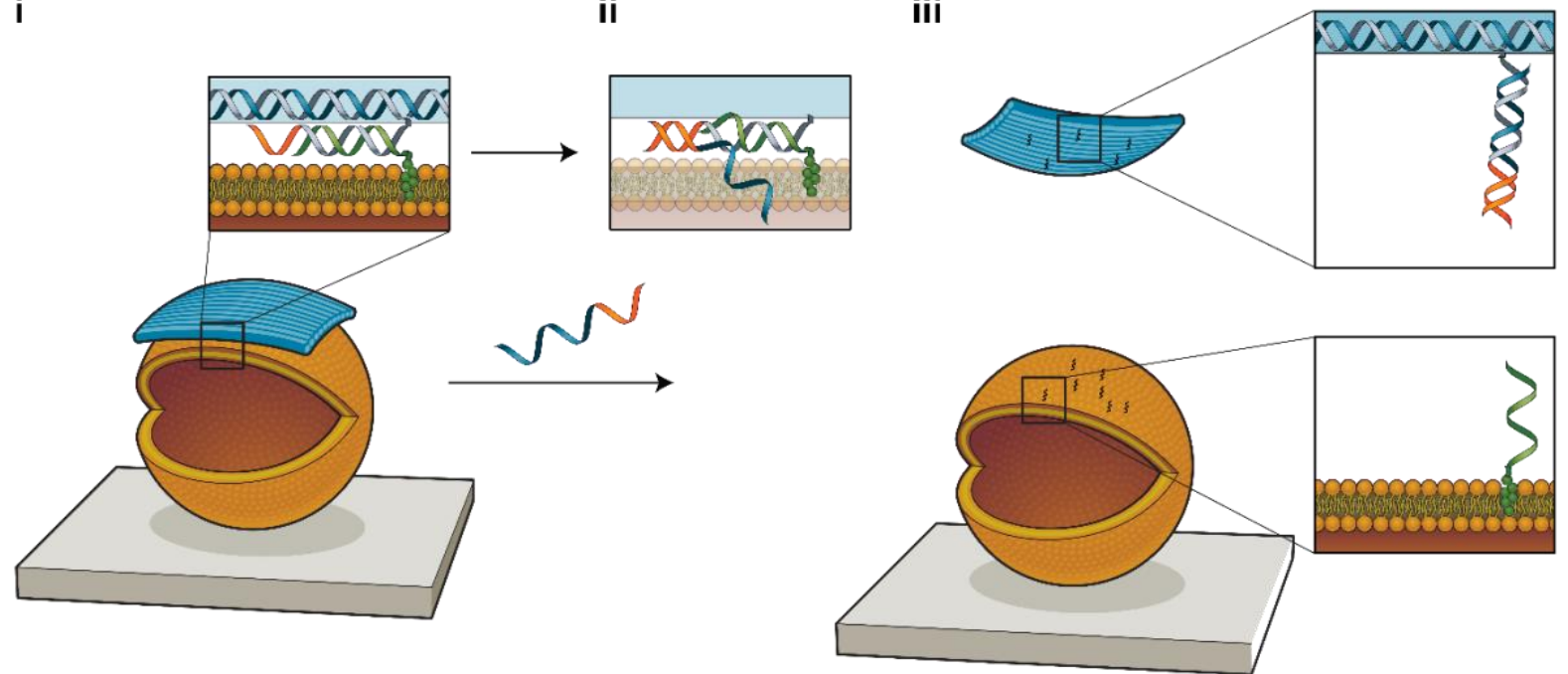

Figure 1: Reversible liposome binding of a DNA origami nanostructure. (A) (i) Schematic of the DNA origami tile. (ii) TEM image of the DNA origami tile. (iii) Averaged TEM image of tile obtained using RELION. Two different averaged structures were obtained, with minor differences resulting from staining. (iv) Zoom of TEM images of the tile. (B) Schematic showing attachment of cholesterol and fluorescently labelled DNA strands to tile. (i) Cholesterol labelled strand C2 hybridises with handle $\mathrm{H} 1$ on the tile. (ii) Cy5 labelled strand F2 hybridises with handle $\mathrm{H} 2$ on the tile. (iii) Cholesterol labelled strand $\mathrm{C} 1$ hybridises with handle $\mathrm{H} 1$ on the tile, as well as Cy5 labelled strand F2. (iv) Structure of TEG-cholesterol modified DNA. (C) (i) Schematic of the binding of the tile (blue) to a liposome (orange). Inset: Schematic showing the DNA strand extending from the tile (grey), which is hybridised to a cholesterol strand (green) and has 
a toehold (orange) for strand displacement. Cholesterol is shown embedded in the lipid bilayer. (ii) Upon addition of a displacement strand (blue-orange), branch migration initiates. (iii) When strand displacement is complete, the tile is released from the liposome and the cholesterol-DNA remains attached. 


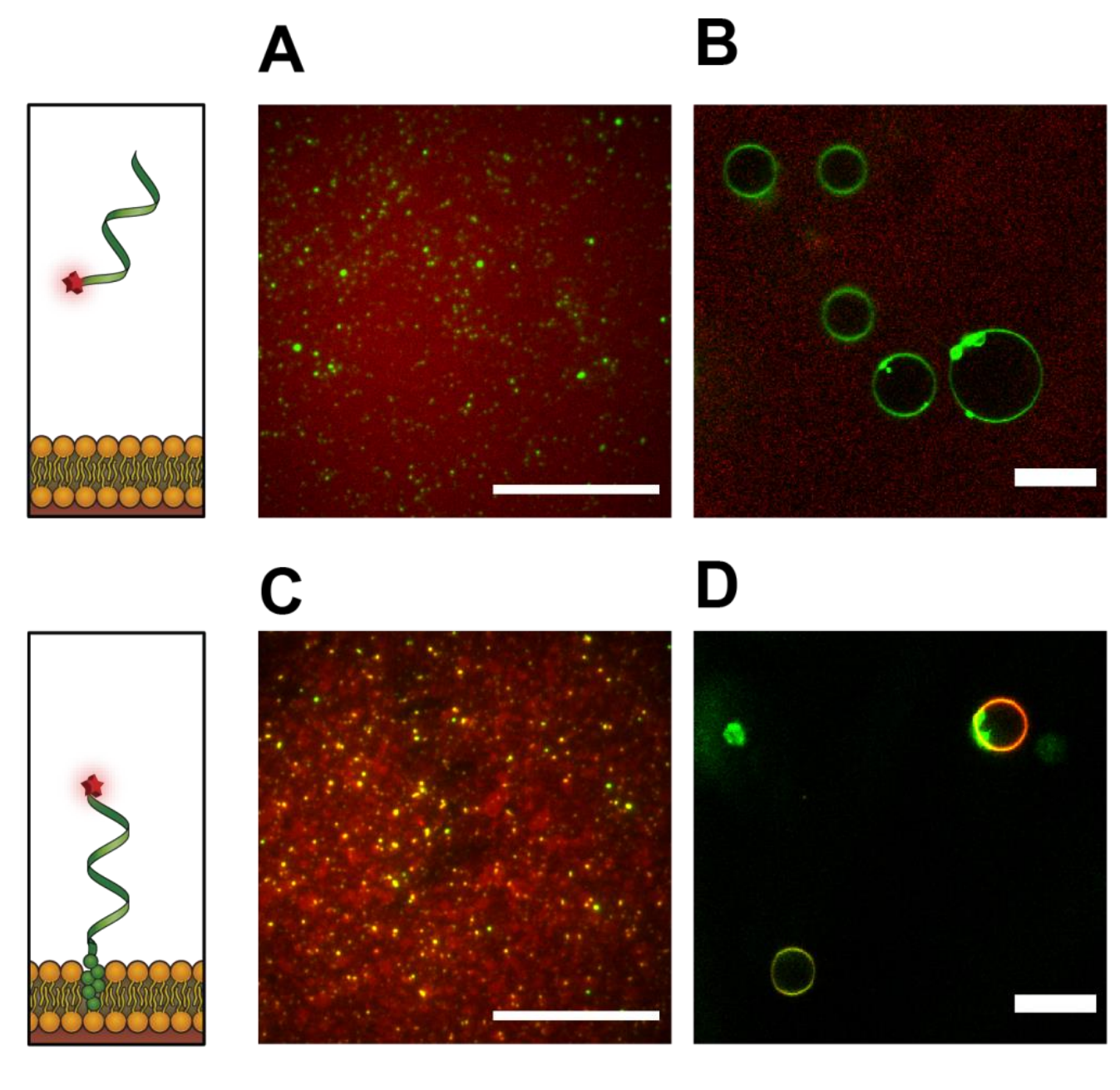

Figure 2: Merged two-colour images of Cy5-tagged DNA (red) at $5 \mathrm{nM}$ concentration and PERhodamine-doped DOPE/DOPC liposomes (green). (A) TIRF image of ssDNA with no cholesterol tag in solution around extruded liposomes without binding. (B) Confocal image of ssDNA with no cholesterol tag in solution around GUVs without binding. (C) TIRF image of cholesterol-tagged ssDNA bound to tethered extruded liposomes (D) Confocal image of cholesterol-tagged ssDNA at bound to tethered GUVs. Scale bars: $20 \mu \mathrm{m}$. 


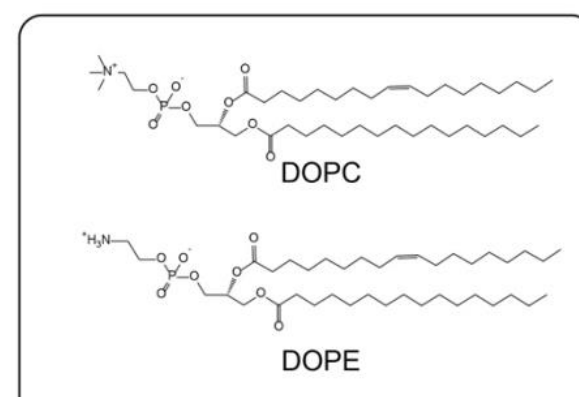

A

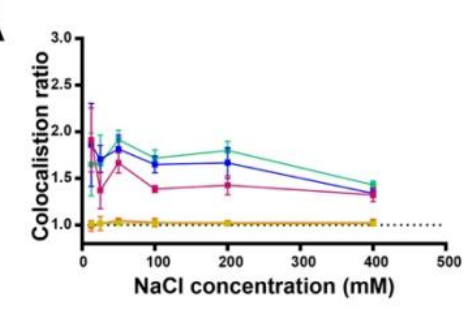

C

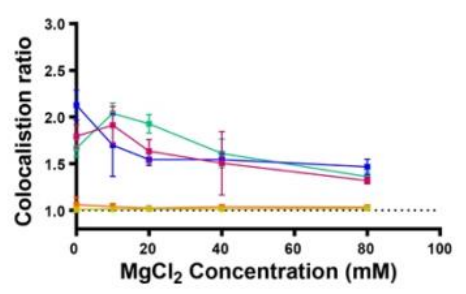

$\mathbf{E}$

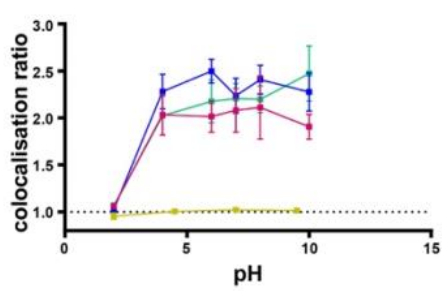

G

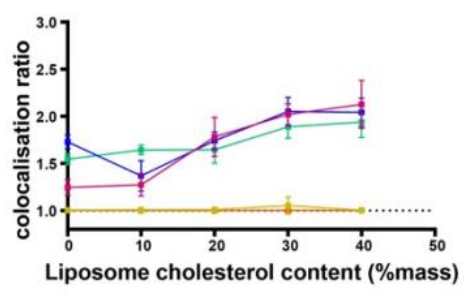

B
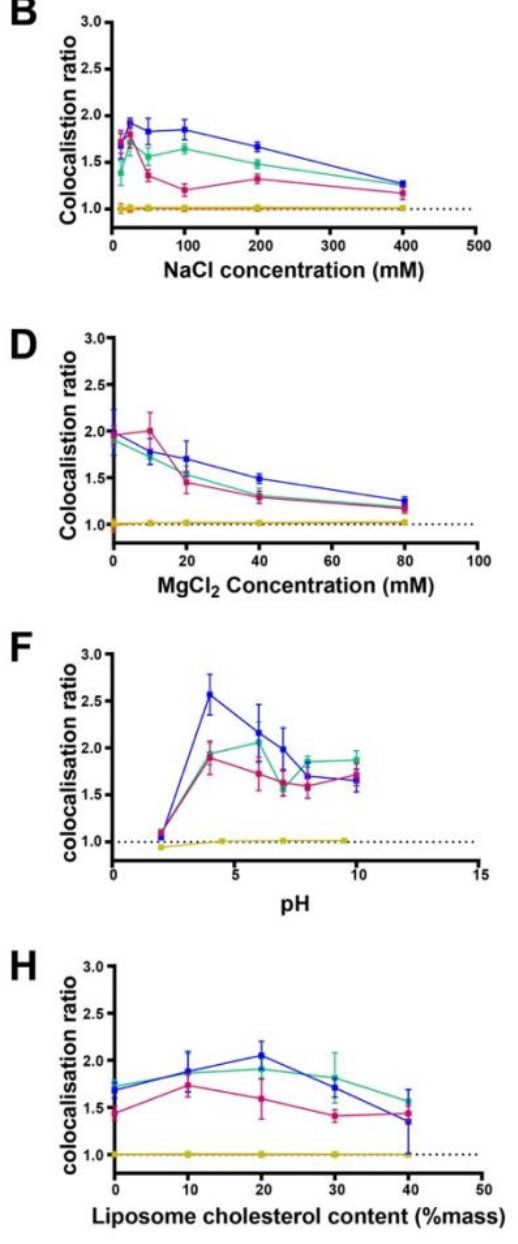

I
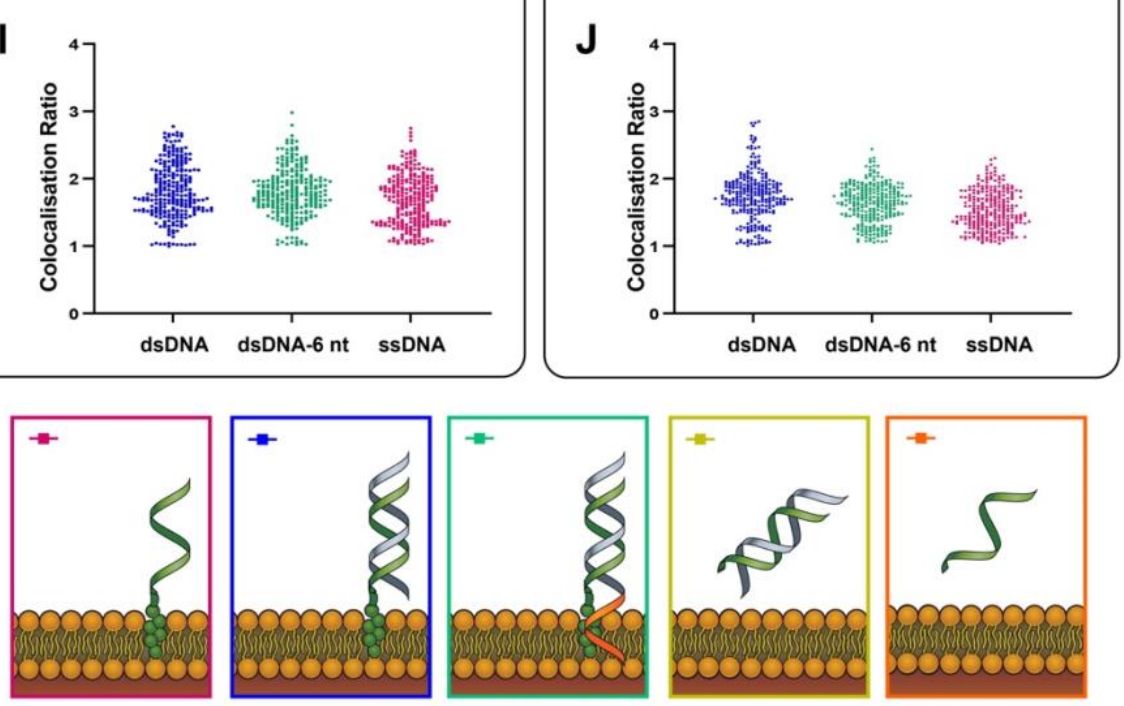

DOPE/DOPC Liposomes

DPhPC Liposomes 
Figure 3: The effect of $\mathrm{NaCl}, \mathrm{MgCl}_{2}, \mathrm{pH}$, and membrane cholesterol on DNA-liposome colocalisation. Colocalisation ratios and standard deviations are shown for Alexa647-labelled cholesterol-tagged single stranded DNA (ssDNA, pink), cholesterol-tagged double stranded DNA (dsDNA, blue) and cholesteroltagged double stranded DNA with a 6 nt overhang (dsDNA-6nt, green) as well as dsDNA with no cholesterol tag (yellow) and ssDNA with no cholesterol tag (orange) and rhodamine-labelled DOPE/DOPC liposomes (left column, A/C/E/G) and DPhPC liposomes (right column, B/D/F/H). Solution conditions tested included: (A/B) extrusion buffer [NaCl] containing 12.5, 25, 50, 100, 200 and $400 \mathrm{mM} \mathrm{NaCl}$, (C/D) extrusion buffer [MgCl2] containing 0, 10, 20, 40 and $80 \mathrm{mM} \mathrm{MgCl} 2$, and (E/F) extrusion buffer [pH] adjusted to $\mathrm{pH}$ values of $2,4,6,7,8$ and 10 . (G/H) The effect of lipid cholesterol content was tested by forming liposomes from DOPE/DOPC and DPhPC lipid stocks containing $0,10,20,30$ or 40\% cholesterol. $(\mathrm{I} / \mathrm{J})$ Distribution of $\mathrm{C}_{R}$ values for each cholesterol-tagged DNA configuration across all conditions $(\mathrm{n}=$ 264; DOPE/DOPC: dsDNA = $1.82 \pm 0.41 ;$ dsDNA-6nt = 1.80 $\pm 0.35 ;$ ssDNA 1.68 $\pm 0.37 ;$ DPhPC: dsDNA = $1.74 \pm 0.36$, dsDNA-6nt $=1.64 \pm 0.28$, ssDNA $=1.54 \pm 0.29$, all mean $\pm S D$ ). For both lipid types and with or without overhang, ssDNA vs dsDNA showed a significant difference in mean (Wilcoxon rank sum test, $p<0.05)$. For DPhPC there was a small but significant difference in mean between dsDNA and dsDNA-6nt (Wilcoxon rank sum test, $\mathrm{p}<0.05$ ), however for DOPE/DOPC there was no significant difference between the two dsDNA configurations. 
A
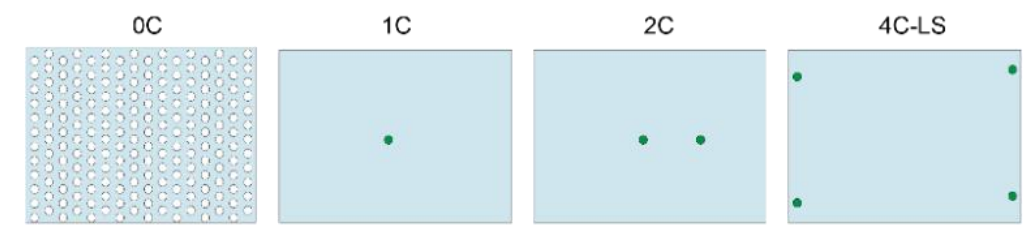

$=$ available staple extension

4C-SS

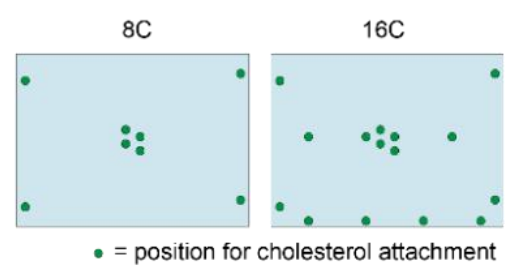

B i.

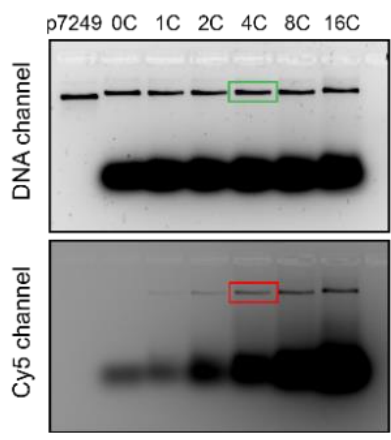

ii.

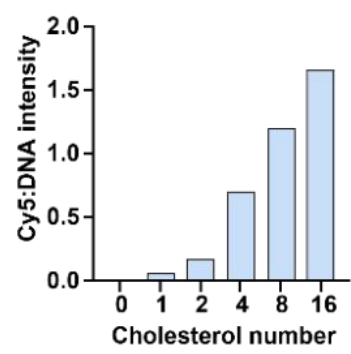

c i.

i.

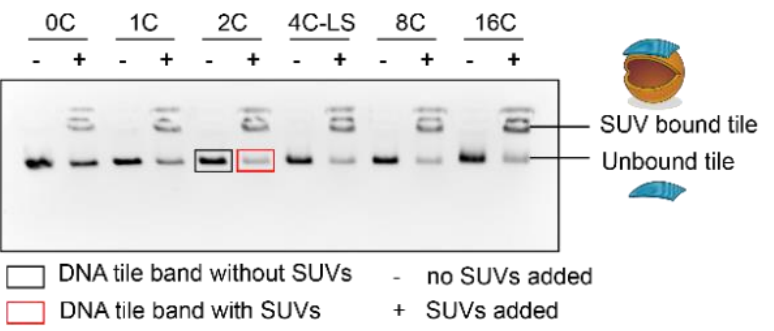

ii.

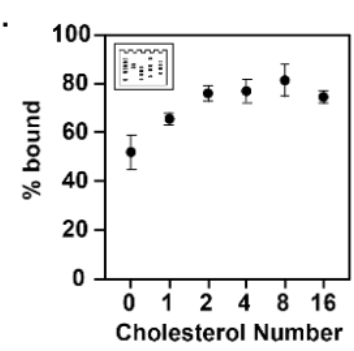

iii.

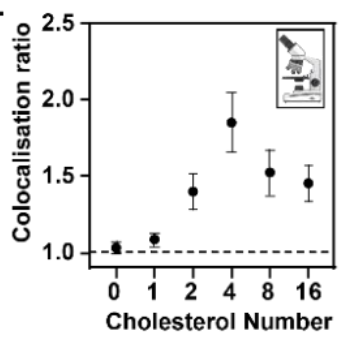

D i.

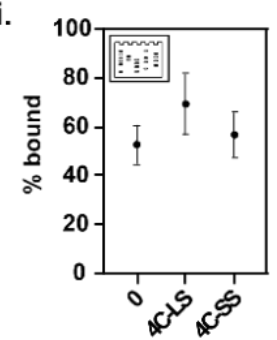

Cholesterol Configuration

ii.

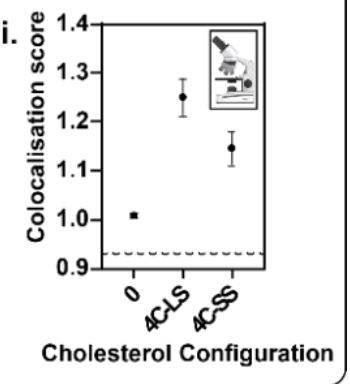

Figure 4: Effect of number and arrangement of cholesterols on DNA origami binding to liposomes. (A) The different attachment points available on the DNA origami tile for staple extensions (white circle) and the points selected for staple extension of handles $\mathrm{H} 1$ (green circle) for cholesterol attachment. Light blue rectangle represents the tile. The name of the different attachment points is given on top of each tile. (B) Validation of cholesterol attachment to the tile for different cholesterol numbers. (i) Gel image. DNA and Cy5 channels which represent the tile and Cy5 fluorophore, respectively are shown. The integrated band intensity in the Cy5 channel (red box) is divided by the integrated band intensity in the DNA channel (green box) to obtain the ratio of Cy5:DNA intensity. This is summarised in chart (ii). (C) The effect of cholesterol number on membrane binding. (i) Gel image. (ii) Percentage bound from the gel analysis calculated from ratio of integrated band intensity in the presence of liposomes (red box) to the integrated band intensity in the absence of liposomes (black box). (iii) Colocalisation ratios from microscopy. (D) The effect of cholesterol configuration on membrane binding. (i) Percentage bound obtained gel analysis. (ii) Colocalisation ratios from microscopy. 
A

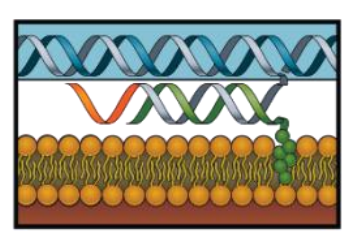

Dt1.4

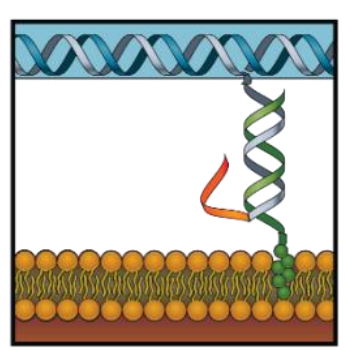

Pt8.5

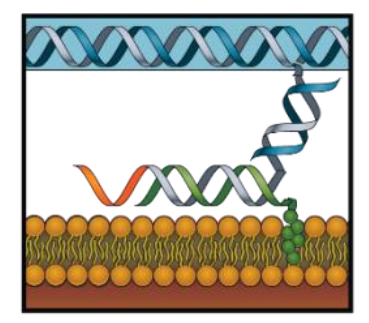

Dt6.1

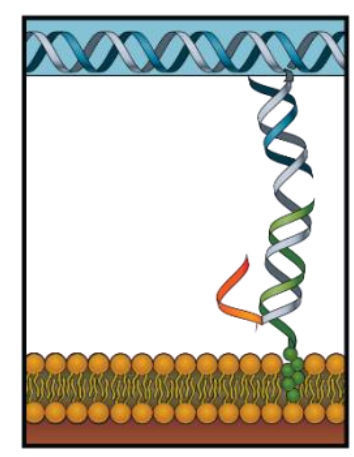

Pt13.2

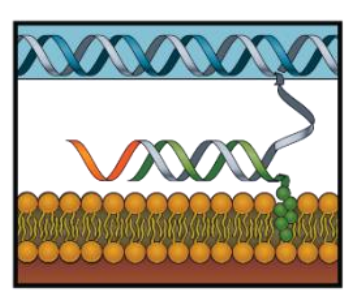

Dt8.1

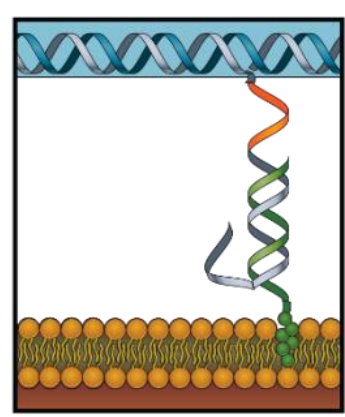

Dt15.2
B i

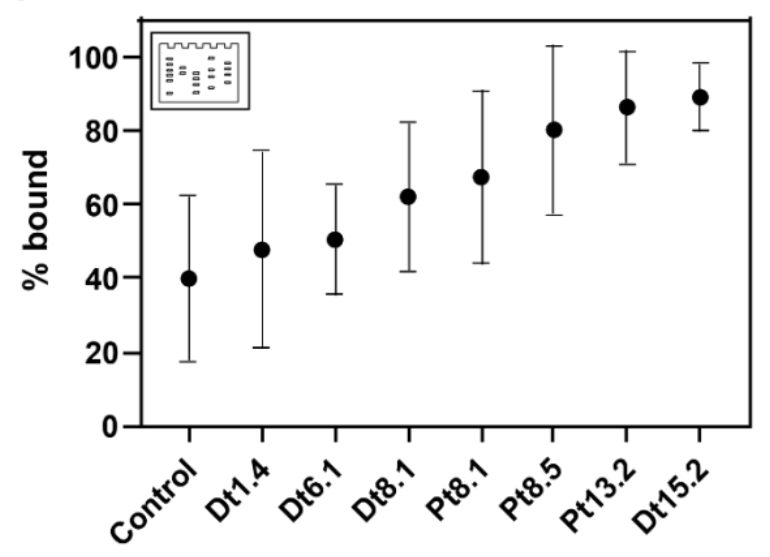

ii

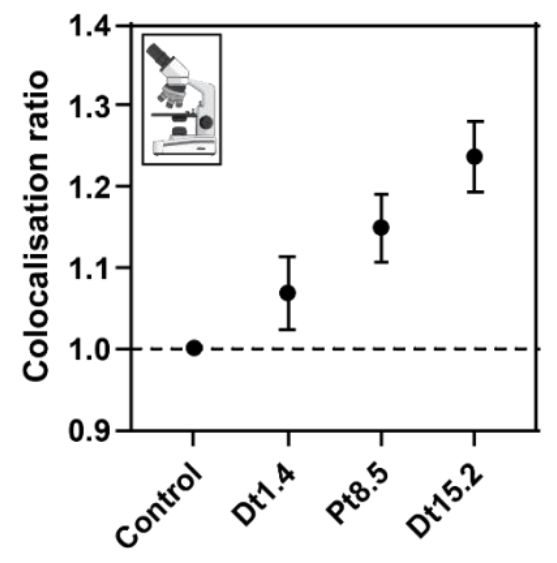

Figure 5: Effect of spacing and linker length between cholesterol and DNA origami tile on binding to liposomes. (A) Schematics for the different designs for cholesterol attachment to the tile and its membrane binding. The distance between the cholesterol and the tile is given below the design schematic. (B) The effect of spacing between cholesterol and tile on the membrane binding. (i) Percentage bound obtained from gel analysis. (ii) Colocalisation ratios from microscopy. 
A i

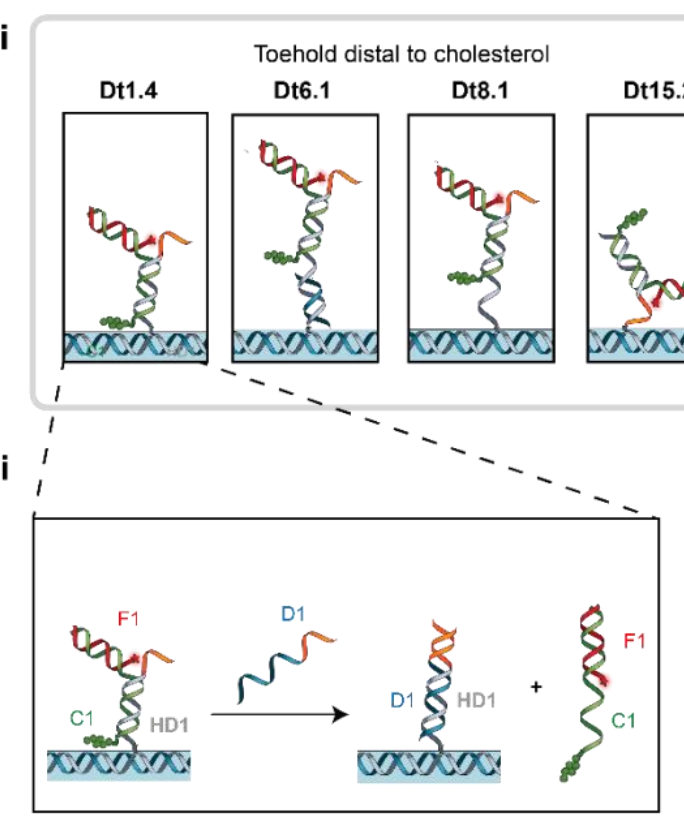

iii

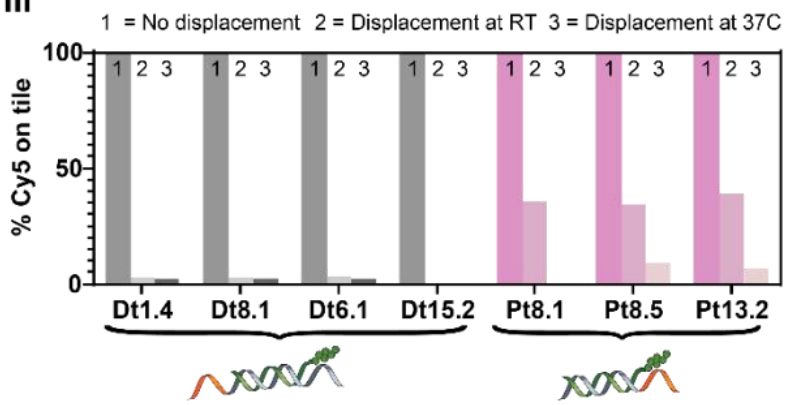

B i

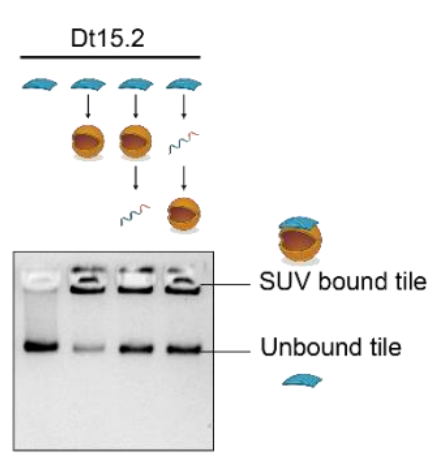

ii

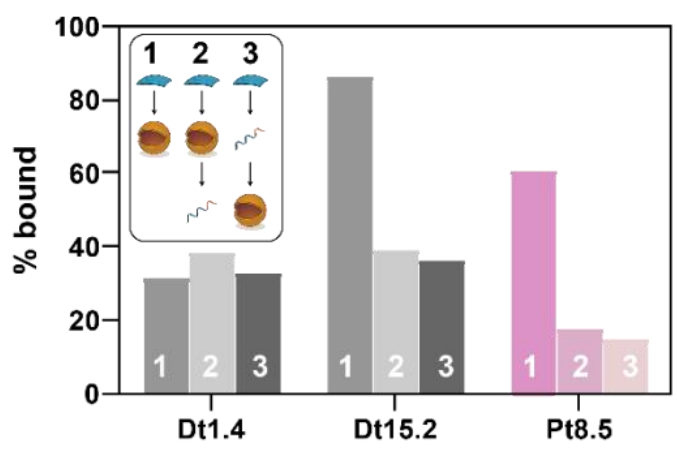

Figure 6: Effect of toehold position on strand displacement release of DNA tiles from liposomes. (A) (i) Schematics for the different designs for cholesterol attachment to the tile. (ii) Example strand displacement mechanism resulting in the detachment of the Cy5 labelled strand from the tile, shown here for Design Dt1.4. (iii) Bar chart showing the percentage of Cy5 attached to the tile under different displacement conditions. In the control, no displacement strand is added, RT and $37^{\circ} \mathrm{C}$ represent displacement at room temperature and $37^{\circ} \mathrm{C}$, respectively. Designs with toeholds distal from the cholesterol groups are shown in shades of grey. Designs with toeholds proximal to the cholesterol groups are shown in shades of pink. (B) Strand displacement of membrane-bound tiles. (i) Gel image. (ii) Percentage of tiles bound to the SUVs tabulated from the gel analysis. Designs with toeholds distal from the cholesterol groups are shown in shades of grey. Designs with toeholds proximal to the cholesterol groups are shown in shades of pink. 
bioRxiv preprint doi: https://doi.org/10.1101/2020.06.01.128686; this version posted April 9, 2021. The copyright holder for this preprint (which was not certified by peer review) is the author/funder, who has granted bioRxiv a license to display the preprint in perpetuity. It is made available under aCC-BY 4.0 International license. 


\section{REFERENCES}

1. Seeman,N.C. and Sleiman,H.F. (2018) DNA nanotechnology. Nature Reviews Materials, 3, 17068.

2. Seeman,N.C. (1982) Nucleic acid junctions and lattices. Journal of theoretical biology, 99, 237-247.

3. Pinheiro,A.V., Han,D., Shih,W.M. and Yan,H. (2011) Challenges and opportunities for structural DNA nanotechnology. Nature Nanotechnology, 6, 763-772.

4. Wang,P., Meyer,T.A., Pan,V., Dutta,P.K. and Ke,Y. (2017) The beauty and utility of DNA origami. Chem, 2, 359-382.

5. Daljit Singh,J.K., Luu,M.T., Abbas,A. and Wickham,S.F.J. (2018) Switchable DNA-origami nanostructures that respond to their environment and their applications. Biophys Rev, 10, 1283-1293.

6. Zhang,D.Y. and Winfree,E. (2009) Control of DNA Strand Displacement Kinetics Using Toehold Exchange. J. Am. Chem. Soc., 131, 17303-17314.

7. Qian,L. and Winfree,E. (2011) Scaling Up Digital Circuit Computation with DNA Strand Displacement Cascades. Science, 332, 1196-1201.

8. Storm,G. and Crommelin,D.J. (1998) Liposomes: quo vadis? Pharmaceutical Science \& Technology Today, 1, 19-31.

9. Dou,Y., Hynynen,K. and Allen,C. (2017) To heat or not to heat: Challenges with clinical translation of thermosensitive liposomes. Journal of controlled release, 249, 63-73.

10. Veronese,F.M. and Harris,J.M. (2002) Introduction and overview of peptide and protein pegylation. Advanced drug delivery reviews, 54, 453-456.

11. Chung,Y.H., Beiss, V., Fiering,S.N. and Steinmetz,N.F. (2020) COVID-19 Vaccine Frontrunners and Their Nanotechnology Design. ACS Nano, 14, 12522-12537.

12. Bell,N.A. and Keyser,U.F. (2014) Nanopores formed by DNA origami: a review. FEBS letters, 588, 35643570.

13. Akbari,E., Mollica,M.Y., Lucas,C.R., Bushman,S.M., Patton,R.A., Shahhosseini,M., Song,J.W. and Castro,C.E. (2017) Engineering Cell Surface Function with DNA Origami. Advanced Materials, 29.

14. Franquelim,H.G., Khmelinskaia,A., Sobczak,J.-P., Dietz,H. and Schwille,P. (2018) Membrane sculpting by curved DNA origami scaffolds. Nature communications, 9, 811.

15. Grome,M.W., Zhang,Z., Pincet,F. and Lin,C. (2018) Vesicle Tubulation with Self-Assembling DNA Nanosprings. Angewandte Chemie International Edition, 57, 5330-5334.

16. Burns,J.R., Stulz,E. and Howorka,S. (2013) Self-Assembled DNA Nanopores That Span Lipid Bilayers. Nano Lett., 13, 2351-2356.

17. Langecker,M., Arnaut,V., Martin,T.G., List,J., Renner,S., Mayer,M., Dietz,H. and Simmel,F.C. (2012) Synthetic lipid membrane channels formed by designed DNA nanostructures. Science, 338, 932-936.

18. Diederichs,T., Pugh,G., Dorey,A., Xing,Y., Burns,J.R., Nguyen,Q.H., Tornow,M., Tampé,R. and Howorka,S. (2019) Synthetic protein-conductive membrane nanopores built with DNA. Nat Commun, 10, 1-11. 
19. Burns,J.R., Seifert,A., Fertig,N. and Howorka,S. \%J N. nanotechnology (2016) A biomimetic DNA-based channel for the ligand-controlled transport of charged molecular cargo across a biological membrane. 11, 152.

20. Mendoza,O., Calmet,P., Alves,I., Lecomte,S., Raoux,M., Cullin,C. and Elezgaray,J. (2017) A tensegrity driven DNA nanopore. Nanoscale, 9, 9762-9769.

21. Shen,Q., Grome,M.W., Yang,Y. and Lin,C. (2020) Engineering Lipid Membranes with Programmable DNA Nanostructures. Advanced Biosystems, 4, 1900215.

22. Göpfrich,K., Li,C.-Y., Ricci,M., Bhamidimarri,S.P., Yoo,J., Gyenes,B., Ohmann,A., Winterhalter,M., Aksimentiev,A. and Keyser,U.F. (2016) Large-conductance transmembrane porin made from DNA origami. ACS nano, 10, 8207-8214.

23. Khmelinskaia,A., Franquelim,H.G., Petrov,E.P. and Schwille,P. (2016) Effect of anchor positioning on binding and diffusion of elongated 3D DNA nanostructures on lipid membranes. Journal of Physics $D$ : Applied Physics, 49.

24. Kielar,C., Xin,Y., Shen,B., Kostiainen,M.A., Grundmeier,G., Linko,V. and Keller,A. (2018) On the Stability of DNA Origami Nanostructures in Low-Magnesium Buffers. Angewandte Chemie International Edition, 57, 9470-9474.

25. Nakano,S., Fujimoto,M., Hara,H. and Sugimoto,N. (1999) Nucleic acid duplex stability: influence of base composition on cation effects. Nucleic acids research, 27, 2957-2965.

26. Böckmann,R.A., Hac,A., Heimburg,T. and Grubmüller,H. (2003) Effect of sodium chloride on a lipid bilayer. Biophysical journal, 85, 1647-1655.

27. Velikonja,A., Perutkova,̌̌., Gongadze,E., Kramar,P., Polak,A., Maček-Lebar,A. and Iglič,A. (2013) Monovalent ions and water dipoles in contact with dipolar zwitterionic lipid headgroups-theory and MD simulations. International journal of molecular sciences, 14, 2846-2861.

28. Xu,W., Nathwani,B., Lin,C., Wang,J., Karatekin,E., Pincet,F., Shih,W. and Rothman,J.E. (2016) A Programmable DNA Origami Platform to Organize SNAREs for Membrane Fusion. J. Am. Chem. Soc., 138, 4439-4447.

29. Cocucci,E., Aguet,F., Boulant,S. and Kirchhausen,T. (2012) THE FIRST 5 SECONDS IN THE LIFE OF A CLATHRIN COATED PIT. Cell, 150, 495-507.

30. Ohmann,A., Göpfrich,K., Joshi,H., Thompson,R.F., Sobota,D., Ranson,N.A., Aksimentiev,A. and Keyser,U.F. (2019) Controlling aggregation of cholesterol-modified DNA nanostructures. Nucleic Acids Res, 47, 11441-11451.

31. Zadeh,J.N., Steenberg,C.D., Bois,J.S., Wolfe,B.R., Pierce,M.B., Khan,A.R., Dirks,R.M. and Pierce,N.A. (2011) NUPACK: Analysis and design of nucleic acid systems. Journal of computational chemistry, 32, 170173.

32. Kreir,M., Farre,C., Beckler,M., George,M. and Fertig,N. (2008) Rapid screening of membrane protein activity: electrophysiological analysis of OmpF reconstituted in proteoliposomes. Lab on a chip, $\mathbf{8}$, 587-595.

33. Baker,M.A.B., Nieves,D.J., Hilzenrat,G., Berengut,J.F., Gaus,K. and Lee,L.K. (2019) Stoichiometric quantification of spatially dense assemblies with qPAINT. Nanoscale, 11, 12460-12464. 
34. Jungmann,R., Avendaño,M.S., Woehrstein,J.B., Dai,M., Shih,W.M. and Yin,P. (2014) Multiplexed 3D cellular super-resolution imaging with DNA-PAINT and Exchange-PAINT. Nature methods, 11, 313318.

35. Schindelin,J., Arganda-Carreras,I., Frise,E., Kaynig,V., Longair,M., Pietzsch,T., Preibisch,S., Rueden,C., Saalfeld,S. and Schmid,B. (2012) Fiji: an open-source platform for biological-image analysis. Nature methods, 9, 676-682.

36. Dunn,K.W., Kamocka,M.M. and McDonald,J.H. (2011) A practical guide to evaluating colocalization in biological microscopy. American Journal of Physiology-Cell Physiology, 300, C723-C742.

37. Rothemund,P.W.K. (2006) Folding DNA to create nanoscale shapes and patterns. Nature, 440, 297-302.

38. Arnott,P.M., Joshi,H., Aksimentiev,A. and Howorka,S. (2018) Dynamic Interactions between LipidTethered DNA and Phospholipid Membranes. Langmuir, 34, 15084-15092.

39. Lanphere,C., Offenbartl-Stiegert,D., Dorey,A., Pugh,G., Georgiou,E., Xing,Y., Burns,J.R. and Howorka,S. (2021) Design, assembly, and characterization of membrane-spanning DNA nanopores. Nature Protocols, 16, 86-130.

40. Deplazes,E., Poger,D., Cornell,B. and Cranfield,C.G. (2018) The effect of hydronium ions on the structure of phospholipid membranes. Physical Chemistry Chemical Physics, 20, 357-366.

41. Douglas,S.M., Dietz,H., Liedl,T., Högberg,B., Graf,F. and Shih,W.M. (2009) Self-assembly of DNA into nanoscale three-dimensional shapes. Nature, 459, 414-418.

42. Tsui,Fran.C., Ojcius,D.M. and Hubbell,W.L. (1986) The intrinsic pKa values for phosphatidylserine and phosphatidylethanolamine in phosphatidylcholine host bilayers. Biophysical journal, 49, 459.

43. Róg,T., Pasenkiewicz-Gierula,M., Vattulainen,I. and Karttunen,M. (2009) Ordering effects of cholesterol and its analogues. Biochimica et Biophysica Acta (BBA)-Biomembranes, 1788, 97-121.

44. Yang,S.-T., Kreutzberger,A.J.B., Lee,J., Kiessling,V. and Tamm,L.K. (2016) The Role of Cholesterol in Membrane Fusion. Chem Phys Lipids, 199, 136-143.

45. Tristram-Nagle,S., Kim,D.J., Akhunzada,N., Kučerka,N., Mathai,J.C., Katsaras,J., Zeidel,M. and Nagle,J.F. (2010) Structure and water permeability of fully hydrated diphytanoyIPC. Chemistry and physics of lipids, 163, 630-637.

46. Huang,J., Buboltz,J.T. and Feigenson,G.W. (1999) Maximum solubility of cholesterol in phosphatidylcholine and phosphatidylethanolamine bilayers. Biochimica et Biophysica Acta (BBA)Biomembranes, 1417, 89-100.

47. Ohmann,A., Li,C.-Y., Maffeo,C., Nahas,K.A., Baumann,K.N., Göpfrich,K., Yoo,J., Keyser,U.F. and Aksimentiev,A. (2018) A synthetic enzyme built from DNA flips 107 lipids per second in biological membranes. Nature Communications, 9, 2426.

48. Roy,R., Hohng,S. and Ha,T. (2008) A practical guide to single-molecule FRET. Nature methods, 5, 507-516.

49. Ma,D., Xu,C., Hou,W., Zhao,C., Ma,J., Huang,X., Jia,Q., Ma,L., Diao,J. and Liu,C. (2019) Detecting SingleMolecule Dynamics on Lipid Membranes with Quenchers-in-a-Liposome FRET. Angewandte Chemie, 131, 5633-5637. 
50. Krishnan,S., Ziegler,D., Arnaut,V., Martin,T.G., Kapsner,K., Henneberg,K., Bausch,A.R., Dietz,H. and Simmel,F.C. (2016) Molecular transport through large-diameter DNA nanopores. Nature communications, 7, 12787.

51. List,J., Weber,M. and Simmel,F.C. (2014) Hydrophobic actuation of a DNA origami bilayer structure. Angewandte Chemie - International Edition, 53, 4236-4239.

52. Baker,M.A.B., Tuckwell,A.J., Berengut,J.F., Bath,J., Benn,F., Duff,A.P., Whitten,A.E., Dunn,K.E., Hynson,R.M., Turberfield,A.J., et al. (2018) Dimensions and Global Twist of Single-Layer DNA Origami Measured by Small-Angle X-ray Scattering. ACS Nano, 12, 5791-5799. 